\section{New Promising Citrus Triploid Hybrids Selected from Crosses between Monoembryonic Diploid Female and Tetraploid Male Parents}

\author{
G. Reforgiato Recupero, ${ }^{1}$ G. Russo, and S. Recupero \\ Istituto Sperimentale per l'Agrumicoltura, Acireale, Corso Savoia, 190, \\ 95024 Italy
}

Additional index words. mandarin, blood oranges, seedlessness

\begin{abstract}
The breeding of citrus triploid hybrids started at Istituto Sperimentale per l'Agrumicoltura spell out in Acireale, Italy, in 1978 (Starrantino and Reforgiato, 1981). The strategy used has been to cross a monoembryonic $2 \mathrm{x}$ female parent with a $4 \mathrm{x}$ male parent. The imbalance between the embryo and endosperm ploidy (3:4) makes seeds from such crossings incapable of germinating in vivo. However, in vitro cultivation has been used to rescue the embryos. In this paper we report the main characteristics of triploid hybrids from 22 different parents, including sweet orange [Citrus sinensis (L.) Osbeck], mandarin $(C$. reticulata Blanco), clementine $(C$. reticulata Blanco), grapefruit $(C$. paradisi Macf.), pummelo $[C$.maxima $]$, tangor $(C$. reticulata $\times C$. sinensis), lemon $[C$. limon $(\mathrm{L})$. Burm. f.], citron ( $C$. medica L.), and Fortunella hindsii (Champ.) Swing. Tetraploid parents are duplex because they originate from the doubling of chromosome number of the nucella or of other somatic tissues. The segregation and recombination process results in triploid hybrids with characteristics that are nearer to the $4 x$ parent than the $2 x$ one. This strategy is important in obtaining seedless hybrids similar to a parent after generations of backcrossing.
\end{abstract}

Over the last few years the citrus market worldwide has required easy peeling and seedless citrus fruit. Many cultivated varieties of orange, clementine and grapefruit are seedless, whereas the number of seeds in mandarin and mandarin-like fruit often makes them less consumer friendly. Many breeding programmes have isolated mandarin diploid hybrids possessing good characteristics, but the fact they are not seedless has jeopardised their market potential. Recently the popularity of 'Avana' mandarin and the 'Monreal' clementine in the Italian citrus industry has progressively declined as a consequence of the seedless clementine selections ('Comune', 'Nules', 'Oroval', 'Oronules', 'Hernandina', etc.). Seedlessness in $2 \mathrm{x}$ Citrus is related to male or female gametophyte sterility, selfincompatibility and early embryo abortion. Iwamasa (1966) listed some cases of pollen sterility (asynapsis, translocation and inversion). Temperature during gametes formation can influence the grade of sterility of many varieties. Seedlessness linked to self-incompatibility is greatly influenced by the presence of allocompatible foreign pollens. This has become a major problem in clementine plantings when they are grown near other varieties of mandarins ('Nova' or 'Fortune'). Cross-pollination results in seedy fruit and commercialisation is jeopardised.

Triploidy has been used in banana, plaintain, watermelon and grape to produce seedless fruit.

Received for publication 5 Aug. 2004. Accepted for publication 13 Sept. 2004.

${ }^{1}$ To whom reprint requests should be addressed; e-mail breedcitr@mail.gte.it. advantages using this strategy are reported.

Strictly monoembryonic $2 \mathrm{x}$ female parents were used to prevent nucellar seedlings in progenies. All the tetraploids used as parent were selected during the breeding programme at the ISA, Acireale, Italy (Russo and Torrisi, 1951b). Most were derived from spontaneous doubling of the chromosome number in the nucellar tissue. Cavone lemon $4 \mathrm{x}$ was recovered from a sprout in the bud union. Their status has been cytologically verified. They were consequently duplex tetraploids. Embryonic incapacity to germinate in vivo caused by the ratio of ploidy level (3:4) between embryo and endosperm (Esen et al., 1978) was overcome by in vitro rescue of the embryos recovered 3 to 4 months after pollination (Starrantino and Reforgiato Recupero, 1981). The possibility of recovering embryos removed from mature fruit was assessed later. Table 1 lists the parents used and the number of triploid hybrids growing in the 'Palazzelli', 'Fonte Ciane' (Syracuse, Italy), and 'S.Gregorio' (Reggio Calabria, Italy) experimental fields. All triploids growing in the field have been grafted to sour orange or citrange rootstocks to reduce the risk of Phytophthora infections.

\section{Hybrids Released}

'Tacle' (Starrantino, 1999) and 'Clara' (Starrantino, 1994) are triploids derived from clementine 'Monreal' and 'Tarocco' tetraploid oranges, whereas 'Camel' comes from 'Nules' clementine and 'Avana' tetraploid mandarin. The tree of 'Tacle' is vigorous and thorny, the canopy is like the 'Tarocco' orange. The fruit is easy-peeling, like a clementine in shape and has smooth, dark orange peel. Colour and flavour resembles 'Tarocco' orange more than clementine but is sweeter. Color-break occurs in mid-November. Ripening occurs between mid-December and mid-January in Italy, when the pulp develops the characteristic anthocyanin pigmentation.

The tree of 'Clara' is not very vigorous and has few thorns. The fruit is large, generally obovoid to slightly oblate to almost subglobose in shape, slightly pigmented and juicy. It ripens between mid-January and February in Italy and tastes like a mix between clementine and orange.

The tree of 'Camel' is similar to 'Avana' mandarin, but is very thorny, especially on vigorous branches. The fruit is medium in size, obovoid-subglobose in shape, pale-orange in colour and easy-peeling. It tastes like a mixture of 'Avana' mandarin and clementine. Ripening period is between mid-December and January in Italy.

'Reale' (Fig. 1) is a triploid hybrid derived from 'Monreal' clementine $\times$ Fortunella hindsii $4 \mathrm{x}$ and has been propagated for its ornamental value because of its continuous blooming and early fruiting (from the first year after grafting). It is used as an ornamental potted tree. Its leaves are more like those of kumquat than those of clementine, its canopy is compact and its thorns are short and thin. Fruit do not exceed $15 \mathrm{~g}$, are yellowish, obovoid and remain on the tree long after physiological maturity. 


\begin{tabular}{|c|c|c|c|c|c|c|c|c|c|c|}
\hline$\frac{\text { Male parent } 4 \mathrm{x} \rightarrow}{\text { Female parent } 2 \mathrm{x} \downarrow}$ & $\begin{array}{l}\text { 'Biondo' } \\
\text { orange }\end{array}$ & $\begin{array}{l}\text { 'Tarocco' } \\
\text { orange }\end{array}$ & $\begin{array}{l}\text { 'Sanguinello'، } \\
\text { orange }\end{array}$ & $\begin{array}{c}\text { Ovaletto } \\
\text { 'Sanguigno' } \\
\text { orange }\end{array}$ & $\begin{array}{l}\text { 'Avana' } \\
\text { mandarin }\end{array}$ & Grapefruit & $\begin{array}{l}\text { 'Cavone' } \\
\text { lemon }\end{array}$ & $\begin{array}{l}\text { 'Monachello' } \\
\text { lemon }\end{array}$ & $\begin{array}{l}\text { 'Doppio } \\
\text { Lentini' } \\
\text { lemon }\end{array}$ & $\begin{array}{l}\text { Fortunella } \\
\quad \text { hindsii }\end{array}$ \\
\hline 'Comune' clementine & & 191 & & & 10 & 33 & & & & \\
\hline 'Monreal' clementine & & 67 & 7 & 7 & 36 & 11 & & & & 4 \\
\hline 'Nules' clementine & 146 & 11 & 37 & 14 & 1 & 3 & 36 & & 1 & 4 \\
\hline 'Oroval'clementine & & 102 & 3 & & 22 & 1 & 18 & & 2 & \\
\hline 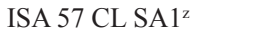 & 35 & & & & & & & & & \\
\hline 'Fortune' mandarin & & 52 & & & 31 & & & & & \\
\hline Pummelo & & 1 & 1 & & & & & & & \\
\hline 'Meyer' lemon & & & & & & & & & 5 & \\
\hline 'Diamante' citron & & & & & & & & & 2 & \\
\hline $1952-36 B-69^{y}$ & & & & & & & & & 27 & \\
\hline 'S. Teresa' lemon & & & & & & & 9 & 6 & & \\
\hline $1964-R I-1 A^{x}$ & & & & & & & 10 & & & \\
\hline
\end{tabular}

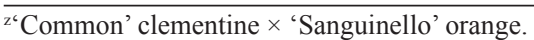

${ }^{y}$ C. limon $\times$ 'Pera del Commendatore'.

x('Femminello' lemon $\times$ 'Cardinale' lemon $) \times$ 'S. Teresa' lemon.

Grafting on alemow (C. macrophylla Wester) achieves the best results for canopy growth with a significantly higher number of fruit than obtained on the other rootstocks (Recupero et al., 2001).

\section{New Hybrids Recently Patented or Considered Promising}

Recently 31 promising hybrids were selected (Table 2) (Russo et al., 2002). Sampling data revealed information on the recommended picking date even if in some cases (C5951 and C6925) total soluble solids and acidity content indicated that the fruit may be ready for picking earlier than the sampling date adopted in the study. However, it must be stressed that the results are preliminary and that long term data observed in different environments and using more replications will allow better assessment and reduce the number of hybrids released.

The fruit of the selected clementine $x$ 'Tarocco' hybrids are generally large with a pigmented pulp due to the presence of anthocyanins. Ripening date, peel thickness, texture and anthocyanin content in peel and pulp in these hybrids differ from 'Tacle' and 'Clara'. Hybrid C2191 (Fig. 2), patented as 'Alkantara', and C1732 (Fig. 3), patented as 'Mandared', have fruit with high anthocyanin content, , are easy peeling like clementine but are larger fruit (Table 2). Fruit of C1829 are distinguished by the fleshy pulp and absence of anthocyanin, whereas $\mathrm{C} 1732$ has anthocyanin in the rind.

Tables 1 and 2 show that Tarocco is the only orange to produce promising or patented hybrids. This underlines the importance of the male genotype compared with the female (clementine) as tetraploidy enhances character transmissibility. Hybrids obtained using other sweet oranges usually produce small fruit, or poor aroma or low TSS to acidity ratio, when pulp firmness is acceptable.

Some hybrids obtained using clementine and 'Fortune' mandarin crossed with 'Avana' mandarin $4 \mathrm{x}$ were very similar to 'Avana' mandarin. Recently, the willow leaf mandarin has lost market favor and the more pigmented and sweeter, seedless clementine selections have become more popular. Some triploids preserve the aroma of 'Avana' but are sweeter and more pigmented and ripen over a long interval. For example, D8811 (Fig. 4) patented as 'Mandalate', is noteworthy because it ripens even later than late ripening 'Ciaculli' mandarins, and it is feasible that the former can be picked as late as April in Italy.

The characteristics of hybrid D2238 are similar to those of grapefruit. Its seedlessness is not unexpected as seedless varieties of grapefruit are very common ('Marsh Seedless', 'Star Ruby'), whereas its early ripening feature is innovative. A previous study on grapefruit (Pennisi, 1974-75) showed that TSS to TAratio of 'Marsh Seedless' grown in the Palazzelli experimental field (Lentini, Italy) was 4.8 in January and 5.9 in February. D2238 had a TSS to TA ratio of 8.9 at the end of January in the same experimental farm and a low naringin content, and consequently did not have the typical sour taste. Its fruit weighed on average $180 \mathrm{~g}$ and were suitable for the fresh fruit market. Juice percentage was $45 \%$. This hybrid seems to be very promising for cultivation as a grapefruit substitute in subtropical climatic areas.

Hybrid C3869 (Fig. 5), patented with the name 'Lemox', is derived from a tetraploidmale parent ('Doppio Lentini' lemon) and 1952-36B-69hybrid(Femminello lemon $\times$ Pera delCommendatore). Pera del Commendatore is a natural hybrid in which lemon, citron and pummelo characters are evident (Zi Niu Deng et al., 1995). Firstobservations on trees growing in an infected area showed a good tolerance of 'Lemox' to natural infections of the mal secco fungus (Phoma tracheiphila).

'Lemox' can be considered the first hybrid to be obtained possessing fruit characteristics resembling those of a true lemon. In addition, its fruit grows fast meaning that this lemon hybrid can be picked early (September) (Table 3 ). In previous $2 \mathrm{x} \times 2 \mathrm{x}$ crosses aimed at transferring the characteristic of resistance to 'mal secco' present in true lemons, the hybrids obtained were practically unusable because their fruit was not like a lemon, even if they showed partial good tolerance to the disease (Russo, 1976).

\section{Some Aspects Concerning the Use of Autotetraploid Male Parents}

Our results emphasize the importance of this breeding program whereby numerous characteristics of the $4 \mathrm{x}$ parent are transferred to the progeny in a single cross, as occurs in some generations of backcrossing diploid species.

The tetraploids used are originated by doubling the chromosome number of the nucella (Russo and Torrisi, 1951) or other somatic tissues. This can lead to duplex autotetraploids

Fig. 1. Nursery tree of 'Reale'('Monreal' clementine $\times$ Fortunella hindsii).

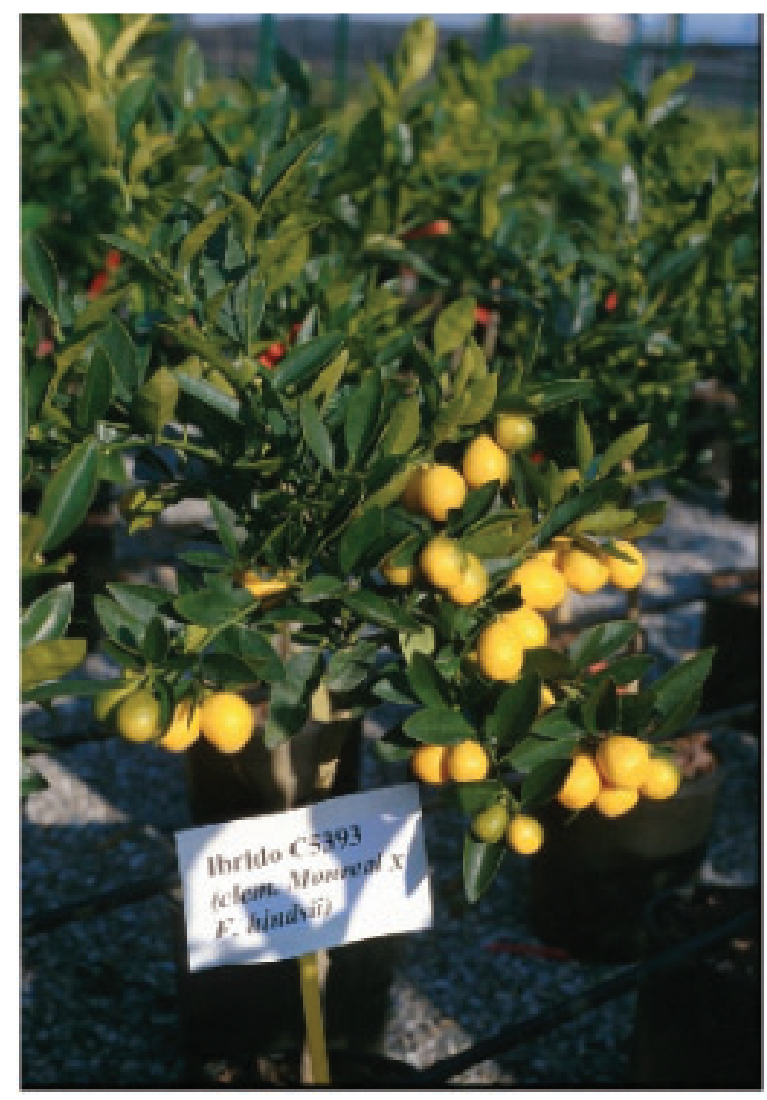




\begin{tabular}{|c|c|c|c|c|c|c|c|c|c|}
\hline Hybrid & Cross $^{2}$ & $\begin{array}{c}\text { Sampling } \\
\text { date }^{y}\end{array}$ & $\begin{array}{c}\text { Fruit } \\
\text { size } \\
(\mathrm{g})\end{array}$ & $\begin{array}{l}\text { Juice } \\
(\%)\end{array}$ & $\begin{array}{c}\text { Total } \\
\text { soluble } \\
\text { solids } \\
(\%)\end{array}$ & $\begin{array}{c}\text { Acidity } \\
(\%)\end{array}$ & S/A & $\begin{array}{c}\text { Epicarp } \\
\text { color } \\
\text { index } \\
(\mathrm{a} / \mathrm{b})\end{array}$ & $\begin{array}{c}\text { Adherence } \\
\text { of } \\
\text { albedo } \\
\text { to pulp }\end{array}$ \\
\hline A 145 & $\mathrm{~A}$ & I & 147.6 & 46.9 & 14.24 & 1.23 & 11.59 & 0.48 & Medium \\
\hline D1469 & A & III & 129.2 & 50.9 & 12.94 & 1.33 & 9.72 & 0.51 & Weak \\
\hline D2273 & A & III & 202.7 & 53.9 & 12.24 & 1.27 & 9.66 & 0.44 & Medium \\
\hline D2281 & A & II & 169.1 & 52.6 & 13.81 & 1.05 & 13.15 & 0.51 & Strong \\
\hline D2414 & A & III & 175.6 & 35.7 & 13.95 & 1.13 & 12.38 & 0.50 & Medium \\
\hline D3681 & A & III & 238.0 & 46.6 & 11.35 & 1.41 & 8.06 & 0.43 & Medium \\
\hline D3755 & A & III & 134.0 & 53.4 & 14.14 & 1.92 & 7.37 & 0.49 & Medium \\
\hline D871 & A & III & 151.2 & 50.5 & 13.85 & 1.79 & 7.73 & 0.45 & Strong \\
\hline E522 & A & II & 213.9 & 43.9 & 12.69 & 0.99 & 12.88 & 0.37 & Medium \\
\hline C641 & B & III & 226.0 & 48.5 & 12.94 & 1.13 & 11.49 & 0.44 & Weak \\
\hline C1829 & B & I & 188.2 & 46.5 & 12.99 & 1.19 & 10.91 & 0.09 & Weak \\
\hline C2899 & B & II & 233.3 & 37.7 & 12.78 & 1.66 & 7.69 & 0.24 & Weak \\
\hline E7003 & $\mathrm{C}$ & II & 211.1 & 43.5 & 14.29 & 1.43 & 9.97 & 0.42 & Medium \\
\hline E968 & $\mathrm{C}$ & II & 168.9 & 57.6 & 12.49 & 1.47 & 8.49 & 0.16 & Strong \\
\hline C1732 Mandared & $\mathrm{D}$ & III & 166.0 & 61.0 & 13.84 & 1.97 & 7.02 & 0.52 & medium \\
\hline C5282 & E & I & 85.0 & 42.1 & 11.94 & 1.10 & 10.85 & -0.05 & Weak \\
\hline C5951 & $\mathrm{E}$ & I & 101.7 & 40.0 & 13.24 & 0.93 & 14.17 & 0.12 & Weak \\
\hline C6925 & $\mathrm{E}$ & I & 98.1 & 41.9 & 14.54 & 1.00 & 14.57 & 0.30 & Weak \\
\hline D9518 & $\mathrm{F}$ & III & 68.5 & 30.5 & 11.35 & 1.11 & 10.19 & 0.54 & Weak \\
\hline D8811 Mandalate & G & IV & 98.0 & 42.0 & 13.9 & 1.38 & 10.07 & 0.41 & Weak \\
\hline D9055 & G & III & 85.8 & 43.4 & 12.05 & 1.09 & 11.07 & 0.39 & Medium \\
\hline D2238 & $\mathrm{H}$ & III & 186.9 & 45 & 11.9 & 1.3 & 8.93 & 0.31 & Strong \\
\hline C3869 Lemox & I & $\mathrm{V}$ & 142.0 & 31 & 9.1 & 6.1 & & & \\
\hline
\end{tabular}

${ }^{\mathrm{z}} \mathrm{A}=($ Comune clementine $\times$ Tarocco orange $4 \mathrm{x}) ; \mathrm{B}=($ Oroval clementine $\times$ Tarocco orange $4 \mathrm{x}) ; \mathrm{C}=($ Monreal clementine $\times$ Tarocco orange $4 \mathrm{x}) ; \mathrm{D}=($ Nules clementine $\times$ Tarocco orange $4 \mathrm{x}) ; \mathrm{E}=($ Oroval clementine $\times$ Avana mandarin $4 \mathrm{x}) ; \mathrm{F}=($ Monreal clementine $\times$ Avana mandarin $4 \mathrm{x}) ; \mathrm{G}=(\mathrm{Fortune}$ mandarin $\times$ Avana mandarin $4 \mathrm{x}) ; \mathrm{H}=($ Monreal clementine $\times$ grapefruit 4x $) ; \mathrm{I}=1952-36 \mathrm{~B}-69($ C. limon $\times$ Pera del Commendatore $) \times$ Doppio Lentini lemon 4x. yI $=29$ Nov. 2001; II = 27 Dec. 2001; III = 24 Jan. 2002; IV = 10 Apr. 2002, V = 7 Oct. 1999.

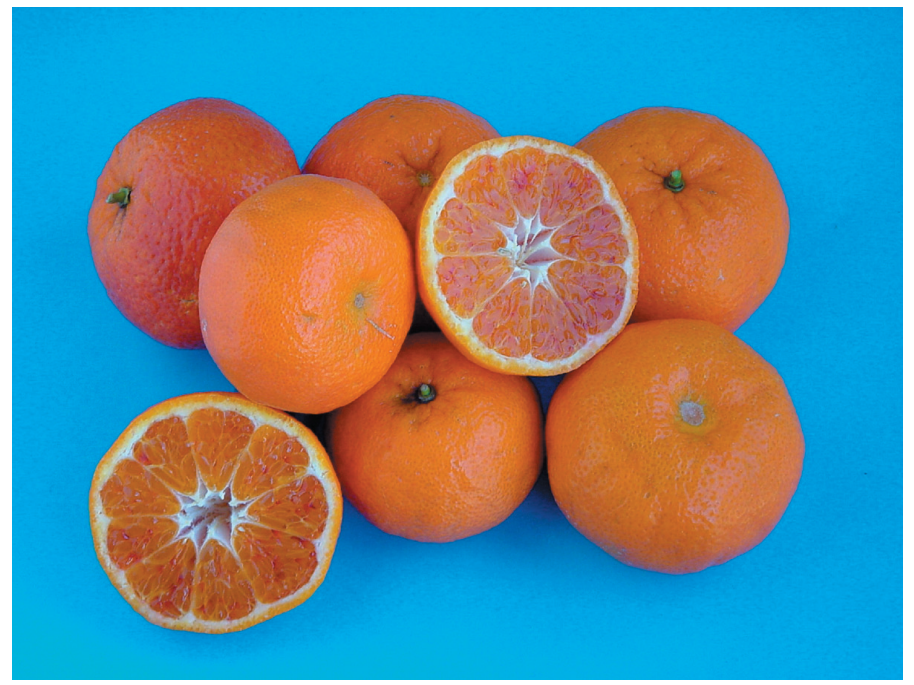

Fig. 2. Fruit of 'Alkantara' ('Oroval' clementine $\times$ 'Tarocco' orange)

where the heterozygote AAaa separates in a 1AA: 4Aa: 1aa ratio, supposing casual separation of chromosomes, so that the recessive homozygote is present in only $16.6 \%$ of the microspores. This explains why the triploid progenies we obtained present lower variability than diploids and why many of the triploid hybrid characteristics are more like those of the male tetraploid parents than the female diploid ones.

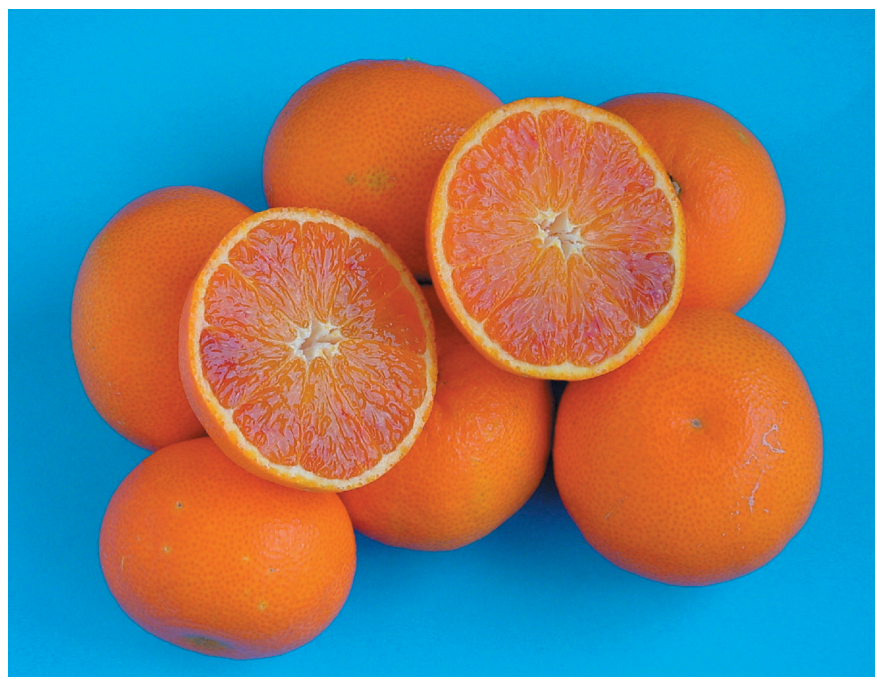

Our observations regarding inheritance of traits are limited to crosses using autotetraploid parents. The use of allotetraploid parents obtained by somatic hybridization in interploid crosses (Grosser et al., 2004) will probably induce a different behavior in the progeny.

The advantages of our strategy over one using $4 \mathrm{x}$ female and $2 \mathrm{x}$ male parents (Esen et al., 1978) is that the former utilises a monoembryonic diploid female parent and obtains hybrids without the interference of nucellar embryos.

In our workploidy analysis on a limited
Fig. 3. Fruit of 'Mandared' ('Nules' clementine $\times$ 'Tarocco' orange).

number of hybrids by chromosome number account and from the trees growing in the field, only triploid level has been observed. However in some years very few hybrids have produced seedy fruit. For instance Tacle and Clara (2000) in the experimental plot produced some seedy fruit. But these hybrids have been verified cytologically as triploids .

Tetraploidy usually produces seedy fruit. Even if we cannot exclude the presence of some 

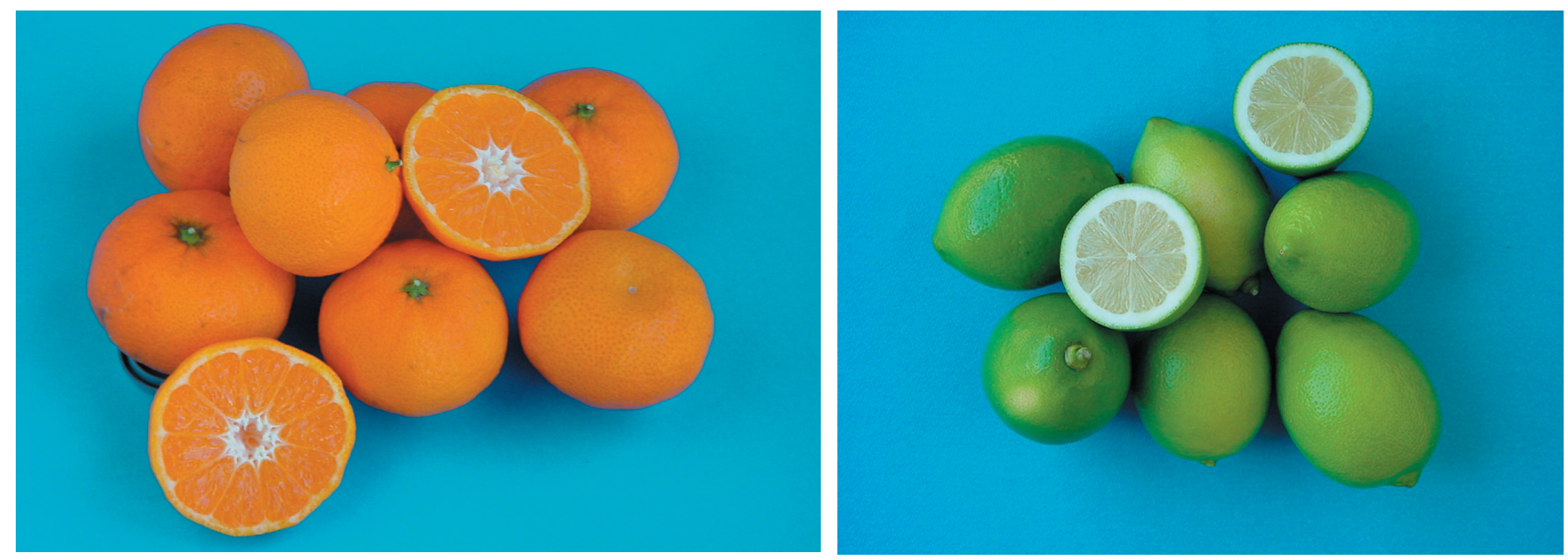

Fig. 4. Fruit of 'Mandalate' ('Fortune' mandarin $\times$ 'Avana' mandarin).

Fig. 5. Fruit of 'Lemox' [('Femminello' lemon $\times$ 'Pera del Commendatore') $\times$ 'Doppio Lentini' lemon].

Table 3. Fruit quality of C 3869 (1952-36B-69 $\times 4 x$ 'Doppio Lentini' lemon).

\begin{tabular}{|c|c|c|c|c|c|c|}
\hline Cultivar & $\begin{array}{l}\text { Sampling } \\
\text { date }\end{array}$ & $\begin{array}{c}\text { Fruit } \\
\text { size }(\mathrm{g})\end{array}$ & $\begin{array}{c}\text { Juice } \\
(\%)\end{array}$ & $\begin{array}{c}\text { Total } \\
\text { soluble } \\
\text { solids } \\
(\%)\end{array}$ & $\begin{array}{c}\text { Acidity } \\
(\%)\end{array}$ & $\begin{array}{c}\text { Seeds } \\
\text { (no.) }\end{array}$ \\
\hline$\overline{\text { C } 3869}$ & 7 Oct. 1999 & 142 & 31 & 9.1 & 6.1 & --- \\
\hline Siracusano lemon & 7 Oct. 1999 & 92 & 28 & 10.3 & 7.9 & 7 \\
\hline C 3869 & 19 Oct. 2000 & 168 & 32 & 7.0 & 6.1 & --- \\
\hline Siracusano lemon & 19 Oct. 2000 & 118 & 31 & 8.8 & 7.4 & 7.5 \\
\hline
\end{tabular}

${ }^{\mathrm{z}}$ Femminello lemon $\times$ Pera del commendatore.

tetraploid genotypes, most of the hybrids tested show characteristics of triploidy. In previous papers (Cameron and Soost, 1969; Esen and Soost, 1972) using monoembryonic seed progenitors, the hybrids were often tetraploid in diploid $\times$ tetraploid crosses. The frequency of tetraploids varied from $6 \%$ to $94 \%$ depending on the pistillate parents used. Differences observed in our crosses may be attributed to the nutrient media or to loss of tetraploid genotypes. After seedlings were transferred to soil, the loss of $10-20 \%$ of hybrids occurred.

Figure 6 shows the distribution of mean weight of the two diploid and the three triploid progenies of clementine x sweet orange. Mean fruit size is 101 and $124 \mathrm{~g}$, respectively in ota and omo diploid crosses, and 194, 201, and $214 \mathrm{~g}$ in triploid crosses $\mathrm{N} \times \mathrm{T}, \mathrm{O} \times \mathrm{T}$ and $\mathrm{C}$ $\times \mathrm{T}$, respectively. Some findings (unpublished data) on crosses between various clementine selections with 'Avana' 4x mandarin revealed that the fruit of the progenies weighs between 100 and $120 \mathrm{~g}$. The possibility of obtaining large fruit is very advantageous in citrus breeding as market demand has swung towards large fruit. Consequently, smaller fruit are losing ground on the fresh fruit market and are not particularly commercialised even if they possess other positive features.

\section{Conclusions}

In triploid progenies the codified characteristics of many genes (fruit size, flavor) that are key factors for breeding programs seem to be strongly influenced by the tetraploid parent. Overall assessment revealed that the only negative features frequently observed during assessment of the triploid progenies were thorniness together with thicker and harder septa segments compared with diploid genotypes. Moreover, other nucellar selections
z'Oroval' clementine $2 \mathrm{x} \times$ 'Tarocco' orange $2 \mathrm{x}$.

'Oroval' clementine $2 \mathrm{x} \times$ 'Moro' orange $2 \mathrm{x}$.

$\mathrm{x}$ 'Nules' clementine $2 \mathrm{x} \times$ 'Biondo' orange $4 \mathrm{x}$.

w'Oroval' clementine $2 \mathrm{x} \times$ 'Tarocco' orange $4 \mathrm{x}$.

${ }^{v}$ 'Common' clementine $2 \mathrm{x} \times$ 'Tarocco' orange $4 \mathrm{x}$.
('Tarocco' 57/1E/1) or diploid hybrids were thorny, but the number of thorns progressively reduced as the tree aged. Cameron and Frost (1968) reported that tendency to low fruityield was a serious problem in triploid progenies. Our results do not rule out the possibility that some hybrids have a low yield, but revealed the triploids and diploids generally gave overlapping yields. Commercial plantations of adult 'Tacle' trees produced $130 \mathrm{~kg}$ yield/tree. The genotype of the male and female parents may greatly influence progeny production.

The main dissimilarity during the evaluation of diploid and triploid progenies is the reduced phenotypic variability of the latter. Therefore, in a genetic breeding programme

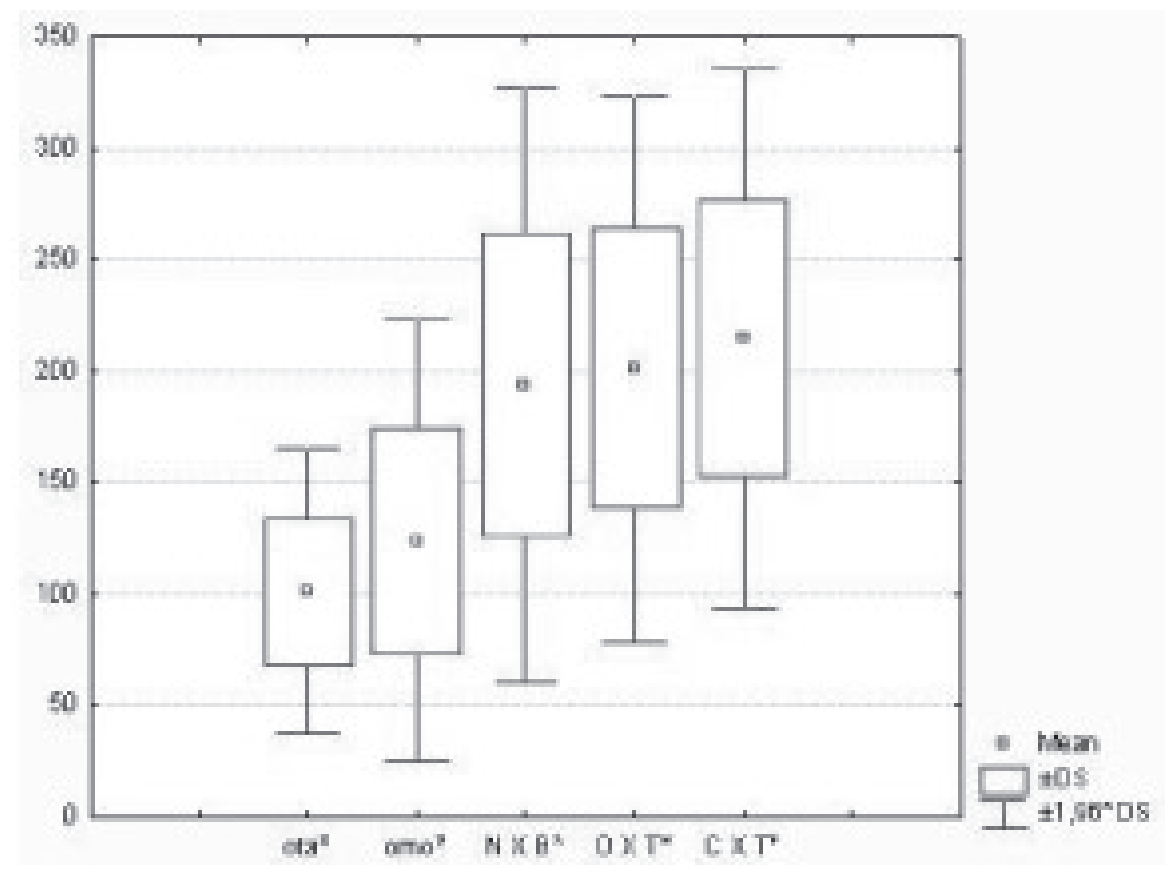

Fig. 6. Distribution of fruit size (g) in diploid and tetraploid progenies. 
using triplody, it is advisable to have a high number of crosses, even if this reduces the number of hybrids obtained per cross. In our breeding programme the most frequently used female parent was the clementine. The numerous hybrids obtained from cross with $4 \mathrm{x}$ 'Tarocco' orange presented similar characteristics, such as large fruit, fair or good easy peeling and different degrees of anthocyanin pigmentation that tended to increase as fruit ripened. Selection of promising hybrids was much more critical and necessitated identification of differences in fruit, and these variations were not always evident and easy to determine. Studies focussed on hybrids that produced fruit with a balanced TSS to acidity ratio, good skin and pulp texture to ensure adequate shelf-life, and good anthocyanin peel and pulp colour. Thick peel is a negative factor because fruit of the same weight have a reduced quantity of pulp. Likewise overly thin peel makes peeling difficult and leads to pulp damage during peeling. Anthocyanin pigmentation in peel and pulp is an indicator of quality as it makes the fruit more attractive and antioxidants are more beneficial to health. However, the presence of excessive concentrations of anthocyanins is correlated with the presence of hydroxycinnamic acids that impart an off-flavor to fruit. The breeding programme carried out by the Istituto Sperimentale per l'Agrumicoltura, Acireale, Italy has selected nearly 900 hybrids (Starrantino, 1992). Other hybrids, besides those described in this paper, show potential. The Istituto Sperimentale per l'Agrumicoltura has agreed to allow promising triploids to be evaluated in diverse environmental areas in South Africa, Spain, California, Chile and Australia.

\section{Literature Cited}

Cameron, J.W. and H.B. Frost. 1968. Genetics, breeding and nucellar embryony, p. 325-370. In: W. Reuther (es.).The citrus industry. vol. 2. Batchelor and Webber.

Cameron, J.W. and R.K. Soost. 1969. Characters of new populations of Citrus polyploids and the relation between tetraploidy in the pollen parent and hybrid tetraploid progeny. Proc. 1st Intl. Citrus Symp. 1:199-205.

Cameron, J.W. and R.K. Soost. 1979. Sexual and nucellar embryony in F1 hybrids and advanced crosses of Citrus with Poncirus. J. Amer. Soc. Hort. Sci. 104 (3):408-410.

Esen, A. and R.K. Soost. 1972. Tetraploid progenies from $2 \mathrm{x} X 4 \mathrm{x}$ crosses of citrus and their origin. J. Amer. Soc. Hort. Sci. 97:410-414.

Esen, A., R.K. Soost, and G. Geraci. 1978. Seed set, size and development after 4x X 2x and 4x X 4x crosses in Citrus. Euphytica 27:283-294.

Grosser, J.W.and J.L. Chandler. 2004. Productionof twelve new somatic hybrid citrus breeding parents with emphasis on late maturity and coldhardiness. J. Amer. Pomol. Soc., 58:21-28.

Iwamasa, M. 1966. Studies on the sterility in genus Citrus with special reference to the seedlessness. The bulletin of the horticultural research station Min. Agr. Fore. Ser. B 6:1-77.

Pennisi, L. 1974-75. Il succo di pompelmo italiano, Annali dell'Istituto Sperimentale per l'Agrumicoltura, VII-VIII:241-256.

Recupero, S., A. Caruso, G. Russo, and G. Reforgiato Recupero. 2001. Osservazioni sul comportamento di diversi agrumi ornamentali. Frutticoltura 11:61-67.

Reforgiato, R.G. and P. Russo. 1992. Percents of nucellar embryony in some hybrid populations of Citrus latipes. Proc. Int. Soc. Citriculture, 1:130-134.

Russo, F. and M. Torrisi. 1951a. Forme tetraploidi in Citrus limon e C. aurantium L. Ann. Sper.
Agr. Roma n.s. 5:13-20.

Russo, F. and M. Torrisi. 1951b. Il poliploidismo nei Citrus autopoliploidi ed allopoliploidi. Ann. Sper. Agr. Roma n.s. 5:1041-62.

Russo, F. and M. Torrisi. 1953. Problemi ed obiettivi di genetica agrumeria. Parte 1. Selezione degli ibridi, degli embrioni nucellari, dei triploidi e provocazione artificiale di mutazioni. Ann. Sper. Agr. Roma n.s. VII:883-906.

Russo, F. 1976-77. Il miglioramento genetico per la resistenza al mal secco del limone in Italia. Annali Ist. Sper. Agrumicoltura. IX-X:231-243.

Russo, G., S. Recupero, D.P. Paolo, and G.R. Recupero, 2002. L'utilizzo della triploidia nel miglioramento genetico degli agrumi.VI giornate Scientifiche SOI, Spoleto, I:23.

Soost, R.K. and J.W. Cameron, 1980. 'Oroblanco' a triploid pummelo-grapefruit hybrid. HortScience 15(5):667-669.

Soost, R.K. and J.W. Cameron, 1985. 'Melogold' a triploid pummelo-grapefruit hybrid. HortScience 29 (6):1134-1135.

Starrantino, A. and G.R. Recupero. 1981. Citrus hybrids obtained in vitro from $2 \mathrm{x}$ females $\times 4 \mathrm{x}$ males. Proc. Intl. Soc. Citricult. 1:31-32.

Starrantino, A. 1992. Use of triploid for production of seedless cultivars in citrus improvement programs. Proc. Intl. Soc. Citricult. 1:117-121.

Starrantino, A. 1994. 'Clara', un ibrido triploide di clementine "Monreal" e di arancio "Tarocco" tetraploide. Atti II Giornate Scientifiche SOI p. $177-178$.

Starrantino, A. 1999. 'Tacle', nuovo ibrido triploide di clementine $\times$ "Tarocco". Frutticoltura. $1: 45-47$.

Zi Niu, D, A. Gentile, E. Nicolosi, G. Continella, and E. Tribulato. 1995. Caratterizzazione del germoplasma di agrumi: dalle descrizioni degli antichi citologi all'analisi del DNA. Italus Hortus 2:68-79. 